\title{
The effect of using games in teaching conservation
}

\author{
Cedric Kai Wei Tan ${ }^{\text {Corresp., }}{ }^{1}$, Jiin Woei Lee ${ }^{2}$, Adeline Hii ${ }^{3}$, Yen Yi Loo ${ }^{4}$, Ahimsa Campos-Arceiz ${ }^{3,5}$, David W \\ Macdonald ${ }^{1}$ \\ ${ }^{1}$ Wildlife Conservation Research Unit (WildCRU), Department of Zoology, University of Oxford, Oxford, United Kingdom \\ 2 Graduate School, University of Nottingham - Malaysia Campus, Selangor Darul Ehsan, Selangor, Malaysia \\ 3 School of Environmental and Geographical Sciences, University of Nottingham - Malaysia Campus, Selangor Darul Ehsan, Malaysia \\ 4 Division of Biology \& Conservation Ecology, School of Science \& the Environment, Manchester Metropolitan University, Manchester, United Kingdom \\ 5 Mindset Interdisciplinary Centre for Tropical Environmental Studies, University of Nottingham - Malaysia Campus, Selangor Darul Ehsan, Malaysia \\ Corresponding Author: Cedric Kai Wei Tan \\ Email address: cedric.tan@zoo.ox.ac.uk
}

Games are an increasingly popular approach for conservation teaching. However, we know little about the effectiveness of the games on students' experiences and knowledge acquisition. Many current games are supplemental games (SG) that have no meaningful interaction with the subject matter. We adapted the experiential gaming (EG) model where students were immersed in goal-orientated tasks found in real-life situations, and they tackled questions to complete actions for their main task. Classroom-based games were created for 8 different conservation topics for an annual Wildlife Conservation Course and an annual Diploma in International Wildlife Conservation Practice. Data were collected over two cycles, a total sample size of 55 multinational students. We used a combination of repeated-measures design and counterbalanced measures design; each student was subjected at least twice to each of the EG and didactic instruction (DI) treatments, and at least once to the SG approach. We compared students' perception, learning and behavioral responses to the treatments, including measures of student personality types and learning styles as explanatory variables. Findings revealed multiple benefits of the classroom EG compared to the DI approach, such as increased attention retention, increased engagement and added intrinsic motivation. The improved level of intrinsic motivation was mainly facilitated by increased social bonding between participants. Further, we show that this experiential gaming approach appeals to a wide range of learning styles and personalities. The performance of SG was generally intermediate between that of EG and DI. We propose EG as a beneficial complement to traditional classroom teaching and current gamified classes for conservation education. 


\section{The effect of using games in teaching conservation}

\section{Cedric Kai Wei Tan ${ }^{a \dagger}$, Jiin Woei Lee ${ }^{b}$, Adeline Hiic, Yen Yi Loo ${ }^{d}$, Ahimsa Campos-}

3 Arceiz $^{\mathrm{c}, \mathrm{e}}$, David W. Macdonald ${ }^{\mathrm{a}}$

5 a Wildlife Conservation Research Unit, Department of Zoology, University of Oxford, The

6 Recanati-Kaplan Centre, Tubney House, Tubney, Oxon OX13 5QL

7 b Graduate School, The University of Nottingham Malaysia Campus, Jalan Broga, 43500

8 Semenyih, Selangor Darul Ehsan, Malaysia

$9{ }^{\mathrm{c}}$ School of Environmental and Geographical Sciences, The University of Nottingham Malaysia

10 Campus, Jalan Broga, 43500 Semenyih, Selangor Darul Ehsan, Malaysia

11 d Division of Biology \& Conservation Ecology, School of Science \& the Environment,

12 Manchester Metropolitan University, Manchester, UK.

13 e Mindset Interdisciplinary Centre for Tropical Environmental Studies, The University of

14 Nottingham Malaysia Campus, Jalan Broga, 43500 Semenyih, Selangor Darul Ehsan, Malaysia

$16 \dagger$ corresponding author

17 email: cedric.tan@,zoo.ox.ac.uk

18 phone number: +447581000703

19

20 Word count: 5996 


\section{Abstract}

Games are an increasingly popular approach for conservation teaching. However, we

24 know little about the effectiveness of the games on students' experiences and knowledge

25 acquisition. Many current games are supplemental games (SG) that have no meaningful

26 interaction with the subject matter. We adapted the experiential gaming (EG) model where

27 students were immersed in goal-orientated tasks found in real-life situations, and they tackled 28 questions to complete actions for their main task. Classroom-based games were created for 8

29 different conservation topics for an annual Wildlife Conservation Course and an annual Diploma

30 in International Wildlife Conservation Practice. Data were collected over two cycles, a total

31 sample size of 55 multinational students. We used a combination of repeated-measures design

32 and counterbalanced measures design; each student was subjected at least twice to each of the

33 EG and didactic instruction (DI) treatments, and at least once to the SG approach. We compared

34 students' perception, learning and behavioral responses to the treatments, including measures of

35 student personality types and learning styles as explanatory variables. Findings revealed multiple

36 benefits of the classroom EG compared to the DI approach, such as increased attention retention,

37 increased engagement and added intrinsic motivation. The improved level of intrinsic motivation

38 was mainly facilitated by increased social bonding between participants. Further, we show that

39 this experiential gaming approach appeals to a wide range of learning styles and personalities.

40 The performance of SG was generally intermediate between that of EG and DI. We propose EG

41 as a beneficial complement to traditional classroom teaching and current gamified classes for

42 conservation education. 


\section{Introduction}

46 Conservation education aims at developing lifelong knowledge and skills relevant for

47 conservation action (Hungerford \& Volk 1990). As the human population continues to increase,

48 intensifying the demand for natural resources, there is an increasing need for improved education

49 and outreach methods to effect attitude and behavioural change. In recent years, many

50 techniques have emerged to integrate the conservation message with forms of delivery that

51 immerse learners in different perspectives. Some of these delivery methods include hands-on

52 activities, role-play and games (Jacobson et al. 2015).

53 When referring to games here, we mean "immersive, voluntary and enjoyable activities in

54 which a challenging goal is pursued according to agreed-upon rules" (Kinzie \& Joseph 2008).

55 Given the potential to enhance engagement and motivation, environmental educators have

56 utilised games to teach and learn (e.g. Hewitt 1997; Bromley 2000). Conservation often involves

57 hard choices, compromises, and even conflict (Redpath et al. 2013), all of which provide rich

58 source material for game creation. By incorporating active learning principles, games can also

59 empower pupils to exercise responsibility for their own lives and for the environment (Tilbury

60 1995). Thus, games can be a powerful tool for demonstrating and teaching conservation concepts

61 to both children and adults (e.g. Project WILD 2007). However, despite their increasing

62 popularity in conservation education (Bång et al. 2009), we are unaware of published empirical

63 evidence on the effectiveness of conservation games. Additionally, when examining the effects

64 of games in education, while some studies have demonstrated benefits (Klein \& Freitag 1991;

65 Wang \& Chen 2010), others have shown negative effects on motivation and performance

66 (Kirriemuir \& McFarlane 2004). This inconsistency could be attributed to a variety of reasons, 
67 from the different game forms to the different personalities and learning styles of the students

68 (Hill et al. 2003; Rapeepisarn et al. 2008; Lara 2013). facts (Boocock 1966; Boocock \& Schild 1968). The nature of these drill and practice games may, unintentionally and as a result of the absence of real consequences when playing the game,

72 73

foster a tendency in the players to attempt actions with little reflection on outcomes. As such, players may simply continue experimenting with different actions until their scores improve. Although these games have the potential to increase engagement in conservation teaching, and the fun of the teaching experience, they can involve competition for extrinsic rewards (points, badges, or token movements) for the participants. Further, they do not provide control over, or responsibility for, the outcome (e.g. Room 10 of Hastings Central School 2013). Games of this genre also have limited interaction with the subject matter. Henceforth, we term such games as supplemental games (SG), implying that while they are additional (and potentially enjoyable and informative) tools for learning, they do not facilitate learning through the play experience. An example of a supplemental conservation game is the 'Freshwater Board Game' where players move around a board and face ecological events that help them advance or move backwards (Room 10 of Hastings Central School 2013). Players learn about freshwater ecosystem but they have no control over their actions or movements which are mainly determined by the dice roll. Another form of gaming, experiential gaming (EG), differs from supplemental gaming in that players learn about the subject matter by participating in or simulating the process and making judgments with consequences (Kiili 2005), for example by managing a population of endangered species. Importantly, experiential gaming emphasizes immediate feedback from players' actions, giving the players relevant challenges while they work towards a goal (Kiili 
90 2005). This experiential gaming model integrates educational theories and game design to

91 facilitate understanding and optimal learning for participants (Kiili 2005). For example, in the

92 board game 'Conservation Crisis', players manage a wildlife reserve with a species on the verge

93 of extinction (Gilhead \& Milburn 2016). They must strive to protect their wildlife and mitigate

94 conservation challenges. Hence, players learn not only about the facts of a case, but also about

95 the challenges faced by conservationists when implementing measures judged necessary to

96 protect wildlife. This type of game emphasises the application of knowledge and students learn

97 about the consequences their actions and decisions (Kiili 2005). Therefore, they are ideal for

98 teaching dynamic and complex systems with time-delays and feedback on decisions.

99 Conservation biology is framed exactly within such a dynamic and complex systems, and

100 therefore is, as we demonstrate here, fertile ground for the development and use of experiential 101 games.

102 The different game forms might also interact with the learning styles and personality

103 traits of learners to give rise to different perceptions, behaviour and degree of learning from

104 individual learners. Previous studies have demonstrated that an individual's academic

105 performance is an outcome of an interplay between the educational method, learning style and

106 personality attributes (Chamorro-Premuzic et al. 2008; Richardson et al. 2012). For example,

107 students with high agreeableness and low neuroticism have been shown to prefer more

108 interactive lessons such as group work and practical teaching (Chamorro-Premuzic et al. 2007).

109 In another study, achievement motivation was positively correlated with the meaning,

110 reproduction and the application-directed learning style, and negatively correlated with the

111 undirected learning style (Busato et al. 1998b). Yet, there have been few studies investigating the

112 interplay between these personal factors and an individual's affinity for the different forms of 
113 games (Hill et al. 2003; Rapeepisarn et al. 2008; Lara 2013). This is pertinent especially in the

114 context of conservation education, which is usually aimed at a large and diverse range of

115 audiences. Our study aims to address this, examining the effectiveness of the different gaming

116 approaches on individuals exhibiting different learning styles as well as personality traits.

117 Research in this area is needed to establish the extent to which games really can

118 contribute to conservation teaching. Here, we tested the effectiveness of different game forms

119 (SG and EG) and compared these with the approach of didactic instruction when teaching

120 conservation. We quantified perception through the use of questionnaires, learning effectiveness

121 with quizzes and behaviour via observations and video-recording. Additionally, we assessed

122 whether these responses to different lesson types were affected by the students' personality types 123 and learning styles.

124

125

126 Methods

127 Participants and course details

128 Our study was conducted on 55 conservation biologists from two courses: a Wildlife

129 Conservation Course organised by Wildlife Conservation Research Unit (WildCRU, University

130 of Oxford) and Nottingham University in Malaysia and the Recanati-Kaplan Centre Postgraduate

131 Diploma in International Wildlife Conservation Practice in Oxford, United Kingdom (Table 1).

132 Personnel were early career conservation biologists who have been working in conservation

133 organisations for fewer than 5 years or were doing their graduate studies in conservation biology.

134 Twenty-one conservation biologists from different countries in Southeast Asia were

135 selected to attend the Wildlife Conservation Course that took place between $19^{\text {th }}$ and $30^{\text {th }}$ January 
136 2015. In 2016, the same course was held again on $4^{\text {th }}$ to $15^{\text {th }}$ January for 16 other participants.

137 This course was held in the University of Nottingham Malaysia Campus (UNMC). Overall,

138 participants consisted of $14(37.8 \%)$ men and $23(61.2 \%)$ women. 1 participant was 16-20 years-

139 old, 16 participants were 21-25 years-old, 12 were 26-30 years-old, 4 were 31-35 years-old and 4

140 were $>35$ years-old. The course comprised topics ranging from concepts in conservation biology,

141 to transferrable and practical skills. This study was approved by the University of Nottingham

142 Malaysia Campus Science \& Engineering Research Ethics Committee (Ref No. JL051115 \&

143 CT011114) and participants involved willingly signed an agreement form prior to the lessons.

144 Another set of participants comprised sixteen international students (eight each for year

1452015 and 2016) attending the 7-month Recanati-Kaplan Centre Postgraduate Diploma in

146 International Wildlife Conservation Practice directed by WildCRU, University of Oxford. Four

147 participants were 21-25 years-old, 10 were 26-30 years-old, 1 was 31-35 years-old and 1 was

$148>35$ years-old. There were 4 men and 4 women each year. The taught Diploma covered a range

149 of subjects in conservation biology. In 3-4 topics of the Diploma, the participants were subjected

150 to different lesson types and data on these participants collected for this study. In year 2016, two

$151 \mathrm{PhD}$ students from the Wildlife Conservation Research Unit attended the lesson for two topics

152 and participated in the games and DI classes. They were included in the study to add to the

153 sample size. This study was approved by the University of Oxford Central University Research

154 Ethics Committee (Ref No: R42538) (Oxford 2017) and participants involved willingly signed

155 an agreement form prior to the lessons. Table 1 summarises the cohort demographics for each

156 course for separate years.

157

158 Personality and learning style questionnaires 
160 their personality traits and learning styles. The Five Personality Factor test, 5PFT" (70

161 statements) is the first published personality questionnaire specifically created to measure the

162 personality traits now known as the big five (Elshout \& Akkerman 1975): agreeableness,

163 conscientiousness, extroversion, neuroticism and openness. The big five model is one of the most

164 established and recognized approaches in measuring individual differences in personality (Costa

$165 \&$ McCrae 1992).

166 A recent review identified 71 different learning style models (Coffield et al. 2004). It can

167 thus be difficult researchers to select an appropriate learning style assessment (Cassidy 2004).

168 We used three criteria to select our learning style model: (1) whether the purpose of the model

169 matches the aim of the study, (2) how extensively the model has been used in past studies and (3)

170 the validity and reliability of the associated instrument (De Bello 1990). Thus, we used the

171 Inventory of Learning Styles (ILS) (120 statements) (Vermunt 1994). This model measured

172 different aspects of processing strategies, regulation strategies, learning orientations and mental

173 models of learning (Vermunt 1994). Vermunt's model of learning has been used widely within

174 the higher education community (Busato et al. 1998a; Boyle et al. 2003) and has been used to

175 examine the relationship between learning style, the big five personality traits and academic

176 performance (Quinn et al. ; Busato et al. 1998b). Students answered the inventory and scores

177 were subsequently calculated for each component of Vermunt's four learning styles: undirected,

178 reproduction-directed, application-directed and meaning-directed.

179 For both questionnaires, statements within each component overlapped considerably and

180 were a mix of positive and negative, increasing the validity and reliability of the assessment 
181 (Mount et al. 1994; Vermunt 1998). Details on the definition of each category of personality and

182 learning style are provided in Supplementary Method S1.

183

184 Lesson types

185 We employed three lesson types: Didactic instruction (DI), supplemental game (SG) or

186 experiential game (EG) for our classes. The guidelines used to create the games are explained in

187 Supplementary Method S1. Each topic was divided into two sessions that had complementary

188 content. For example, the first session on behavioural ecology was about how to conduct

189 behavioural ecological research and second session was on the link between behavioural ecology

190 and conservation biology. Table 2 provides information on the content taught for each session of

191 each topic. For one topic, either one (SG or EG) or two games (SG and EG) were developed.

192 This allowed for comparisons of the students' responses to SG versus DI, EG versus DI or SG

193 versus EG. For the Diploma 2016 students, the R analysis topic had three sessions each with a

194 different lesson type (SG or EG or DI) to examine the response to three lesson types within one 195 topic.

196 All topics were taught by the same tutor, irrespective of lesson type. This minimised any

197 potential confounds when using different tutors. Regardless of the lesson type, the content and

198 concepts taught for each session were the same. To ensure this, we used the same lesson slides

199 for all lesson types, only adding slides to introduce the game in SG and EG. In all lesson types,

200 students were grouped in teams of 2-4 people to discuss questions asked by the tutor and to work

201 on the given tasks. This standardises the number of opportunities to answer questions in all

202 lesson types. 


\section{Experimental design}

205 We adopted two experimental designs to examine the differences between lesson types:

206 repeated-measures design or counterbalanced measures design. In a repeated-measures design, a

207 single group of students was taught the first session with one lesson type (DI, SG or EG) and

208 then the second session with another lesson type (Fig. 1A) (von Ende 2001; Lawal 2014). In a

209 counterbalanced measures design, the class was divided into two groups and both were taught a

210 two-session lesson. During the first session, one group was taught using one lesson type and the

211 other was taught using the other lesson type. In the second session, the treatments were swapped

212 and thus each group experienced both types of lesson in a balanced ordered manner (Fig. 1B)

213 (Shuttleworth 2009a; Shuttleworth 2009b).

214 The design used was dependent on the number of students and the time available. The

215 games required a minimum of 8 players (for 4 teams with at least 2 persons each). Therefore, the

216 repeated measures design was used for the Diploma course as there were only eight students

217 (Tables 1 and 2). We recognize that the repeated-measures design has a limitation in which

218 students' response to the second session depended on the lesson type of the first session, i.e.

219 order effect (von Ende 2001; Lawal 2014). Therefore, when possible, for the same cohort of

220 students, we alternated the order of the lesson type for different topics to minimize potential

221 treatment order effects (Table 2). Because of the limitations in time and resources (one tutor), not

222 all students were exposed to all topics. However, we were able to ensure that all students except

223 for the two PhD students were exposed at least twice to EG, twice to DI and once to SG to allow

224 for within-individual comparisons. The two $\mathrm{PhD}$ students were exposed twice to EG and once to

225 DI lesson types. 

number of students each time as compared to the repeated-measures design. Therefore, the counterbalanced measures design would be limited to the course with more time and with a larger group of students, i.e. the Wildlife Conservation Course. This design reduces the chances of the treatment order influencing the results (Shuttleworth 2009a; Shuttleworth 2009b). For example, the behaviors of the subjects might be affected by the order in which treatments were given, due to fatigue or other reasons. However, due to time limitations, we also used the repeated measures design for a few topics of the Wildlife Conservation Course (one topic in year 2015, two topics in 2016; Tables 1 and 2). Details of the experimental design and order utilized for the different groups of students are provided in Table 2.

\section{Assessment}

Participants were assessed in three ways: (1) perception: via questionnaires administered to participants, collecting data of individual perceptions of each lesson (Supplementary Information S1); (2) behaviour: via observational surveys and video recording during the classroom sessions and; (3) learning: via quizzes pre and post-session to examine the knowledge

242 acquired by each individual. These modes of assessment overlapped considerably and hence

243 served to cross-validate the students' responses to the different lesson types (Dirks et al. 2014).

The questionnaire designed to test students' perceptions was divided into three sections.

247 In the first section, students were asked to compare the lesson to that of a traditional teaching

248 method experienced previously (not during the course) and rate each statement (e.g. amount of 
249 content taught) according to whether they strongly disagreed ( 1 point), disagreed ( 2 points), no

250 difference (3 points), agreed (4 points) and strongly agreed (5 points) (Supplementary

251 Information S1). These statements reflected the wide range of perceptions held by the learners

252 about their behaviour and learning (Black \& Wiliam 1998). In 2014, this first section of the

253 questionnaire was tested on 20 undergraduates of the University of Oxford as well as on 8

254 students of the Diploma course. Subsequently, it was edited by three of our co-authors prior to

255 the conduct of this study (year 2015 onwards). This section was modified slightly after the earlier

256 courses in 2015. The statement 'Degree of connection with peers' was added to the questionnaire

257 after the first course (Wildlife Conservation Course 2015) and the statement 'Appreciation of

258 application' was added for students of 2016. Sections 2 and 3 of the questionnaire were only

259 administered to students of 2016. These extra statements and sections were added after

260 considering the feedback from students in earlier courses in 2015: Students wrote in their

261 feedback that these were the other beneficial aspects of game lessons. The sample sizes for these

262 additional statements of the questionnaire are thus smaller than that of the other statements.

The second section of the questionnaire is a shortened version of the intrinsic motivation

264 inventory (Ryan et al. 1991), which focuses on the degree of intrinsic motivation and its

265 predictors: perceived choice, perceived competence, pressure/tension and social bonding (see

266 Supplementary Method S1 for details). These 4 subscales each had 5 statements which

267 overlapped considerably and were a mix of positive and negative, increasing the validity of the

268 assessment (McAuley et al. 1989; Tsigilis \& Theodosiou 2003). The third section was aimed at

269 measuring interpersonal interactions between students within teams, which is a positive predictor

270 of intrinsic motivation ((Ryan et al. 1991). It was based on the Inclusion of Other in Self (IOS) 
271 Scale (Aron et al. 1992): "Please circle the picture that best describes your relationship to the

272 other participants in your group" (Supplementary File (Questionnaire)).

273

274

(2) Behaviour

275

We noted the frequency of joyful behaviour (smiling, laughing, clapping, cheering),

276

distracted behaviour (yawning, falling asleep expressions, looking at phones), asking questions,

277

and answering questions for each individual (Supplementary File (Behavioural observation

278

sheet). We only recorded asked questions that were relevant to the topic, rather than any

279

questions relating to the game or administration. Behaviours were selected based on three

280

criteria. First, at similar classes prior to the study, a catalogue of the typical students' behaviour

281

was created and refined to answer our research questions (Supplementary File (Behavioural

282

observation sheet). Second, these behaviours complemented the statements used in the

283

perception questionnaire, for example, the "degree of encouragement to ask questions" and

284

hence served to verify the perception response. Third, several of these behaviours have been used

in previous studies on undergraduates to understand student participation (asking and answering

questions, Fritschner 2000; Mustapha 2010) and distraction (phone-using and sleeping, McCoy

2016; Mustapha 2010). Particular behaviours were biased to certain lesson types, e.g. joyful

behaviour is expected to be higher when engaging in a game than when attending a DI lesson.

Nevertheless, we were also interested in examining whether these behaviours were different

between the two game forms. For example, when a SG is distracting, it might elicit fewer joyful

behaviours than a EG lesson. Due to logistical constraints, we did not record behaviour for the $\mathrm{R}$

292 analysis lessons in the Wildlife Conservation Course 2015. Behaviours that occurred for a

293 duration of more than a minute were considered as multiple counts if there was at least a 10-sec 
294 interval between the behaviours (Mahar et al. 2006). To standardise the number of opportunities

295 of asking question, during the DI lessons, questions used in the game lessons were asked

296 verbally and the tutor waited for answers from the participants.

297 Behavioural data were collected via observer note-taking and subsequently verified with

298 video records (Mustapha 2010). Observers were trained prior to lessons to minimise inter- and

299 intra-observer bias. They were trained by JWL at lessons not analysed in this study. Two

300 observers and one observer were employed for observations during the Wildlife Conservation

301 Course and Diploma Programme respectively. Since courses were carried out in different

302 countries, different observers were involved. Therefore, after the courses, another observer who

303 was not involved in direct note-taking made behavioural recordings from the videos filmed

304 during class. Our inter-observer correlation coefficients were $0.71,0.78,0.72$ and 0.80 for

305 Diploma 2015, Diploma 2016, WCC 2015 and WCC 2016 respectively and thus above the

306 recommended criterion of $>70 \%$ or greater (Jonsson \& Svingby 2007). To ensure consistency,

307 we used the behavioural data collected by the last observer for our analyses.

(3) Learning

Quizzes consisted of questions asking facts, meaning or application of topic to a real-

311 world situation. Therefore, a question could be categorised as reproduction-, meaning- or

312 application-based question type, guided by the revised Bloom's taxonomy (Krathwohl 2002) and

313 complementary to the learning styles quantified by Vermunt's Inventory of Learning Styles. The

314 Cognition Process Dimension of the revised Bloom's taxonomy consist of six levels that are

315 defined as Remember, Understand, Apply, Analyze, Evaluate and Create. We only constructed

316 questions that tested the lowest three levels (Remember, Understand, Apply) as the higher three 
317 levels required more complex testing procedures. Our questions on reproduction (remembering)

318 required students to "retrieve, recognize and recall relevant knowledge from memory"

319 (Krathwohl 2002). For example, "what is inbreeding depression?". Our meaning-based questions

320 required learners to "construct meaning from messages through interpreting, exemplifying,

321 classifying, summarizing, inferring, comparing and explaining" (Krathwohl 2002). An example

322 is "What is the difference between raster and vector?". Finally, our application-based questions

323 required students to "carry out or use a procedure in a given situation" (Krathwohl 2002). An

324 example of a question is "How do we apply the stratified random sampling method when

325 interviewing villagers?". The questions were in a multiple-choice format with 4 options, only 1

326 of which was right. There were 10 questions for each quiz, comprising a mixture of question

327 types. The same questions were administered before and after each session. In 2016, a third quiz

328 with the same questions was conducted one week after the lesson to quantify retention of

329 knowledge after a longer period of time (as compared to immediately post-lesson). We

330 determined the difficulty level and discriminatory level of each quiz by calculating the mean and

331 standard deviation of correctness. If a question was more difficult, the mean 'correctness' would

332 be closer to zero and if it were easier, the mean 'correctness' would be closer to one. The larger

333 the standard deviation of correctness, the larger the variation in correctness among students and

334 therefore the more discriminatory the question was.

335

336 Statistical analysis

337 All analyses were conducted using R 3.0.2 and with mixed models due to the repeated 338 measures obtained (Ellison 2017; Tango 2017). To examine the effects of lesson type (DI, SG or

339 EG) on students' perceptions, we used a multinomial mixed model with level of agreement as the 
340 response, lesson type as the fixed factor, and student and topic as random factors. Student was

341 entered as a random factor as there were multiple questionnaires completed by each student (e.g.

342 different sessions but same topic). Topic was entered as a random factor to account for any

343 potential differences among topics. The covariates included were year, course (Wildlife

344 Conservation Course or Diploma), age, gender, teaching experience (yes or no), formal teaching

345 training (yes or no). We used one model for each statement of the perception questionnaire (e.g.

346 Encouragement to ask questions).

347 We analysed the variation in each behaviour (joyful, distracted, question-asking and

348 question-answering) with two analyses: (i) a Generalised Linear Mixed Model (GLMM) with a

349 binomial error distribution, the 'probability of performing the behaviour' as a response variable,

350 and (ii) a Linear Mixed Model (LMM) with a normal error distribution and the 'rate of behaviour

351 per hour' as the response variable, omitting zeros.

352 To examine whether learning effectiveness differed with lesson type for the three topics,

353 we entered in a Generalised Linear Mixed Model, with binomial error distribution, correctness as

354 a response $(1=$ correct; $0=$ wrong), lesson type and period (before or after or one-week post

355 lesson (for 2016 only)) and their interaction as fixed factors, topic and student as random

356 variables. Details on checking for assumption violations, and fixed factors and random factors

357 entered for each analysis are provided in Supplementary Method S1.

358 To account for variation in question difficulty and discriminatory level, we also

359 conducted Generalised Linear Mixed Model analyses with the standardized 'correctness' as the

360 response. That is, each individual response (0 or 1$)$ was standardized to the mean 'correctness'

361 obtained by all individuals answering that question and then we divide this difference by the

362 corresponding standard deviation of the 'correctness'. Therefore, if a question were more 
363 difficult, the mean 'correctness' would be closer to zero and if it were easier, the mean

364 'correctness' would be closer to one.

365

366 Results

367 Perception

368 Overall, students perceived EG as the most beneficial and SG as intermediately beneficial

369 among the lesson types. Students scored EG and SG significantly higher than DI in the following

370 questionnaire statements: 'remembrance of content', 'motivation to learn after lesson', 'broadens

371 perspective', 'nurtures creativity', 'challenging', 'attention retention, 'engagement with tutor'

372 and 'engagement with student' (Fig. 2A-C; Table S1 \& S2). For the statements 'learning from

373 peers' and 'appreciation of application', only EG was scored significantly higher than DI, SG

374 attained an intermediate score between EG and DI (Fig. 2A-C; Table S1). EG was scored

375 significantly higher than SG and DI in the questionnaire statements 'connection with peers' (Fig.

376 2C). SG was scored significantly higher than DI in the questionnaire statement "better

377 understanding'. Lastly, for statements 'amount of content' and 'encouragement to ask questions',

378 no significant differences were found among lesson types (Fig. 2A \& C; Table S1 \& S2).

379 Intrinsic motivation measured only for 2016 students revealed significantly higher scores

380 of 'interest / enjoyment' for EG than for DI (SG attained an intermediate score; Fig. 2D). This

381 self-report measure of intrinsic motivation was not explained by 'perceived competence',

382 'perceived choice' nor 'pressure or tension' which are predictors of intrinsic motivation (Fig.

383 2D). Bondedness rating with peers within the team was significantly higher for EG than for DI

384 (Fig. 2E). 
387 type on overall rating (Undirected learning score*lesson type: $\chi^{2}{ }_{1}=7.29, p=0.026$; Table S1).

388 The correlation between overall rating and 'Undirected learning' scores was negligible for EG, 389 and positive for DI and SG (Fig. S1).

\section{Behaviour}

Similar to the results on perception, students' overall behavioural records were most positive in the EG among the three lesson types. There was a significant difference in the probability of 'asking question', ‘joyful behaviour' and 'distraction' occurring among lesson types. Students displayed a higher probability of question-asking for EG lessons compared to DI and SG lessons, higher probability of joyful behaviour in EG and SG lessons than in DI lessons and higher probability of distracted behaviour in DI than in SG and EG lessons (Fig. 3A; Table S3 \& S4). The frequency of 'joyful' behaviour per unit time was significantly higher in EG compared to SG and DI lessons and the frequency of 'distracted' behaviour per unit time was significantly lower in EG compared to DI lessons (Fig. 3B; Table S3 \& S4).

\section{Learning}

Questions varied in their mean correctness and thus difficulty level (Table S5). They also varied in their standard deviation of correctness and hence level of discrimination (Table S5). On average, questions were sufficiently difficult (mean correctness across lessons ranged from 0.35 to 0.55 ) and were able to discriminate different degrees of learning (standard deviation of

407 correctness across lessons ranged from 0.144 to 0.244 ) (Table S5). 
Overall, there was no significant difference in students' learning among the lesson types.

409 Students scored higher in quizzes after the lesson than before the lesson. One-week post lesson

410 quiz scores varied (only 2016 students), depending on lesson type. The average one-week post

411 lesson scores were similar to that of the after-lesson quiz.

412 When analysing all quiz questions, there was no significant difference in learning

413 effectiveness among lesson types (DI versus SG versus EG), as shown by the lack of interaction

414 between lesson type and period (before or after) on the proportion of quiz answers being correct

$415\left(\chi^{2}{ }_{1}=5.18, p=0.075\right.$; Fig. 4A $)$. This lack of significance of lesson type was consistent across

416 both years (Fig. 4B and 4C; Table S6). However, when examining only reproduction-type

417 questions, there was a significant interaction between lesson type and period on the proportion of

418 quiz answers being correct $\left(\chi^{2}{ }_{1}=30.0, p<0.001\right.$; Table S6): the proportional increase in quiz

419 score was higher for DI and EG than for SG (Fig. S2A). This effect was largely attributed to the

420 quiz performance of 2015 students (Fig. S2Ai and S2Aii). When analysing meaning-directed and

421 application-directed question scores separately, the non-significant interaction between lesson

422 type and period indicate that students performed equally well in these questions despite the

423 lesson type (Fig. S2B and S2C: Table S6).

424 When analysing the variation in standardised score, the results were similar. Among all question

425 types, there was a lack of interaction between lesson type and period (before or after) on the

426 proportion of quiz answers being correct (Table S7). Also, when examining only reproduction-

427 type questions, there was a significant interaction between lesson type and period on the

428 proportion of quiz answers being correct for 2015 students $\left(\chi^{2}{ }_{1}=6.23, \mathrm{p}=0.044\right.$; Table S7).

429

430 


\section{Discussion}

432 We used experiential games (EG) to teach conservation and our results demonstrated

433 multiple benefits of this approach. Based on our behavioural observations and perception data,

434 EGs performed better than DI in retaining the students' attention, increasing their interactions

435 with other students and the tutor, improving intrinsic motivation via social bonding and

436 motivating students to learn more after the lesson. Additionally, these positive effects of EGs

437 were mostly consistent across personalities and learning styles. EG was as effective as DI in

438 learning effectiveness. SGs performed better than DI in a few perception parameters (e.g.

439 motivation to learn more after lesson) and was mostly on par with DI. SG fared worse than DI in 440 reproduction-type quiz scores.

441 A student-focused and flexible environment for learning like EG, could develop

442 intrinsic motivation (Entwistle et al. 2002) and improve the motivation to study and reach

443 success (Diseth \& Martinsen 2003). Our study supports this idea: EG fared better than DI in

444 students' intrinsic motivation and the effect of SG was intermediate between that of EG and DI.

445 Extrinsic rewards such as points and leaderboards used in SG can decrease perceived

446 competence and choice and undermine intrinsic motivation (Deci et al. 1975; Deci et al. 2001).

447 Although we found non-significant differences in perceived competence and choice between SG

448 and EG, there was a trend of SG attaining lower scores than EG in both these parameters.

449 Increased intrinsic motivation may in turn encourage students to adopt a deeper approach

450 towards learning, which is associated with intentions to understand rather than to reproduce the

451 material (Fransson 1977; Vansteenkiste et al. 2006). Moreover, students who prefer teaching

452 methods that are interactive (Chamorro-Premuzic et al. 2007), or that facilitate understanding of

453 relevance (Entwistle \& Tait 1990), are more inclined to use a deep approach. Therefore, we can 
454 capitalise on the positive effects of EGs: increased intrinsic motivation and interaction to

455 encourage a deeper approach to learning. Additionally, EGs are especially appropriate for

456 practical conservation like population management and conflict resolution: the understanding of

457 population dynamics and factors affecting conflict respectively would be necessary to the

458 formulation of appropriate decisions.

EGs are particularly suited to conservation teaching for many reasons. Commercially available EGs such as task-based simulations (e.g. The Sims (Electronic Art 2009)) give players

461 a goal or a choice of multiple aims, and players must act consistently in character to achieve it.

462 The benefit of this open-ended concept is that participants can experiment and fail gently.

463 Similar educational EGs such as a jigsaw puzzle to teach Photoshop skills (Dong et al. 2012) and

464 calibration games to teach calibration (Flatla et al. 2011) work on the same principles of task-

465 based simulation and role-play. They allow for users to experience the process of reaching a set

466 target whilst learning. Indeed, all of these studies demonstrated positive effects in terms of

467 students' perception (Flatla et al. 2011; Smith \& Baker 2011; Dong et al. 2012), and behaviour

468 (Halan et al. 2010; Dong et al. 2012), similar to our findings. The potential role of digital EGs in

469 conservation education has also been recognized for at least 10 years (Brewer 2003). However,

470 research on the effects of using EGs (or games in general) on teaching conservation is lacking.

471 Moreover, seldom are these games designed specifically for the classroom, that is, they are

472 usually computer-based games. This in turn requires a software developer and may also lack

473 real-time interactive feedback from the teacher/peers. Our study demonstrated that the elevated

474 level of intrinsic motivation when playing experiential games (relative to DI lessons) was

475 attributed to increased social bonding with peers. This suggests that EGs might be more

476 beneficial when played in the classroom than on the computer. 
478 than didactic teaching (Garris et al. 2002). Experiential learning is student-centered and allows

479 for constant feedback from the students to the tutor. A DI lesson focuses on one-directional fact

480 learning in which meaning or application of the knowledge content may not be effectively

481 assimilated by students. However, we found that EG is at least as good as DI in improving

482 learning, be it reproduction, meaning or application. This is in contrast with other studies that

483 have demonstrated positive effects of experiential gaming on learning (Flatla et al. 2011; Smith

484 \& Baker 2011; Dong et al. 2012). In these studies, learning was assessed in terms of whether

485 learners were able to perform the task after the lesson (e.g. using a software). Instead, we

486 assessed learning with multiple-choice questions which were focused on testing whether students

487 assimilated the content and concepts taught. Future works could evaluate how well certain tasks

488 were performed by students.

489 Our results demonstrated that students underperformed in reproduction-based quiz

490 questions in SG classes relative to EG and DI classes. Because the challenges and actions in a

491 SG do not incorporate meaningful material on the topic, the SG might be considered a distraction

492 from the learning content and jeopardise the recall capacity of the students. Similarly, another

493 study proposes that the controlling game mechanics of SG can decrease intrinsic motivation and

494 hence reduce exam scores (Hanus \& Fox 2015).

495 Two results on the effects of personality and learning styles on the perception of games

496 are noteworthy. We detected the lack of interaction between personality scores and lesson type

497 on overall questionnaire rating. This could be due to the lack of sensitivity of our experimental

498 design and recording tools (e.g. questionnaire) to detect any differences in perception among

499 personality types. Alternatively, it could suggest that the preference of EG over DI might be 
500 universal across different personality types. These results are contrary to a study showing that

501 agreeableness and neuroticism were positively and negatively associated (respectively) with

502 preference for interactive lessons such as group work (Chamorro-Premuzic et al. 2007). Perhaps

503 the EG approach is both interactive and fun, which might appeal to people with low agreeableness

504 (cynical of the world around them) and high neuroticism (tendency to experience negative

505 emotions very intensely). The undirected learning approach is characterised by a lack of

506 discipline and of interest (Tait \& Entwistle 1996) and has been shown to be associated with poor

507 academic performance (Boyle et al. 2003; Kimatian et al. 2017). Hence, for students with low

508 undirected scores, the preference for EG over SG and DI was not unexpected. SG could be

509 perceived as spontaneous and disorganised and DI could be seen as dry, in contrast to EG where

510 the game is relevant to the topic and students are central to the learning process. It is important to

511 note that the learning style inventory used in this study may not be reflective of the more recent

512 learning style inventories being used, such as the Kolb's experiential learning style inventory

513 (e.g. Tsingos et al. 2015; Özyurt \& Özyurt 2015). Kolb’s experiential learning style inventory

514 focuses on how knowledge is created through experience (Kolb 1984) and might therefore be

515 more suitable for our study on experiential games. Nevertheless, despite the popularity of

516 evaluating learning styles to optimise education, there is little evidence to suggest that matching

517 activities to one's learning styles improves learning (Pashler et al. 2009; An \& Carr 2017).

518 The EG educational approach does not come without caveats. Creating a EG relevant to

519 the topic and obtaining its various game components require more time than swhen preparing a

520 DI lesson. Additionally, the duration of an EG lesson is on average twice that of a typical DI

521 classroom. We suggest ways of minimizing time expenditure in preparing and teaching EG

522 lessons. First, give students a time limit for answering each question (usually 1 minute), this 
523 would make the lesson time-regulated. Second, tutors can focus on teaching important concepts

524 during class and then provide supplementary material for the students to learn more after the

525 class. Nevertheless, when time is limited and when there is large volume of content to be covered

526 (e.g. as dictated by a syllabus), the approach of EG or any form of games might not be suitable.

527 Further, in developing countries where students might not have access to comprehensive libraries

528 or online access to academic material, the content would have to be provided and explained by

529 the teacher face-to-face.

530 We are mindful of potential biases in this study. First, the tutor's self-bias for or against

531 a particular lesson type might affect the students' response to that lesson type. We took

532 precautions to minimise this bias by providing a similar number of opportunities to engage with

533 the tutor in all lesson types (i.e. ask or answer questions). The use of a single tutor had the

534 advantage of avoiding any potential confounds between different tutors. It would nevertheless

535 be interesting to investigate the effect of using multiple tutors, each teaching all lesson types.

536 Second, there might be a selection bias in the students used in this study, i.e. students might

537 have been selected based on whether the game approach would appeal to them. This bias was

538 also minimised. The Wildlife Conservation Course applicants submitted their curriculum vitae

539 and personal statements. Three persons including the tutor graded the applications

540 independently and their scores were averaged to make the final decision. Students in the

541 Diploma programme were selected by an interview panel not including the tutor. Third, the

542 students' self-report of perception might not be accurate. In our study, we found that students'

543 self-assessment of learning using the perception questionnaire was in contrast with the

544 assessment of learning via quizzes. Students' perceived that they had remembered better with

545 games but we found no differences in quiz scores among lesson types. It was therefore 
546 important to verify self-reporting of perception with other modes of assessment such as

547 behavioural observations and quizzes, as in our study.

548 Overall, we have found positive effects of EG over DI. In particular, there was an

549 increased in interest in the topic, motivation to learn and attention retention. In addition, we

550 were better able to engage the students, facilitate social learning and social bonding. The focus

551 shifts from the teacher to the learners, acknowledging the students' voice as central to the

552 learning experience. Today, information is a couple of clicks away and the education system

553 should instead be focused on developing students' creative and communicative skills,

554 motivation to succeed and ability to collaborate with others. Educational reforms and

555 pedagogical research are current hot topics (Swallow 2012; Wagner \& Compton 2015). The

556 aims are to shift from memory-based learning to meaning- and application-focused education,

557 creating innovative thinkers and developing team-players. Experiential gaming is one approach

558 that could cater to these objectives and develop conservation biologists for the modern world.

559 To the best of our knowledge, this is the first study to examine the effects of games on

560 conservation teaching. There is scope for many further studies. The effects of the EG approach

561 could be tested on the general public which might have less interest for the work (in this case

562 biodiversity conservation). We could examine if the EG approach is able to increase intrinsic

563 motivation in non-conservationists, and cultivate people's minds to be more aware and

564 involved in conservation issues. Further, it would be interesting to examine the effects of

565 personality on group dynamics in an EG environment to better understand the interaction

566 between personality traits and group performances (Kramer et al. 2014). Future work should

567 also investigate the long-term effects of the training such as students' application of the

568 acquired skills and friendship bonds. 
570 Conclusions

571 EG provides a novel approach to conservation teaching. Despite the extra time needed for

572 the tutor and for the lesson, our findings demonstrate the many benefits for the students as

573 compared to DI. Conservation games, if used appropriately, can play an important role in making

574 conservation more interesting and immersive. EG could also be an educational approach towards

575 building capacity among conservationists in both NGOs and governmental organizations, and

576 perhaps to engage multinational citizens and professionals with biodiversity conservation.

577

578 Acknowledgements

579 We would like to thank the University of Nottingham Malaysia Campus for providing the ethics

580 approval and facilities for the Wildlife Conservation Course. We would also like to thank the

581 observers that have helped collected data on behaviours: ATM Perera, C Lim, A Lee, LY Chou,

582 ABM Alias, WL Poh, MM Weerabangsa, MB Mahadzir, HK Wong, JY Ong and J Moore, the

583 game designers E Arraut and J Lynch and teaching assistants J Wadey, A Tan, EP Wong and N

584 Hii. A Hughes and L Porter.

585

586

587

588

\section{References}

589 An D, Carr M. 2017. Learning styles theory fails to explain learning and achievement:

590 Recommendations for alternative approaches. Personality and Individual Differences

591 116: 410-416. 
592 Aron A, Aron EN, Smollan D. 1992. Inclusion of Other in the Self Scale and the structure of 593 interpersonal closeness. Journal of Personality and Social Psychology 63:596.

594 Bång M, Svahn M, Gustafsson A. 2009. Persuasive design of a mobile energy conservation game 595 with direct feedback and social cues. Breaking New Ground: Innovation in Games, Play, Practice and Theory. Proceedings of DiGRA 2009.

Black P, Wiliam D. 1998. Assessment and Classroom Learning. Assessment in Education: Principles, Policy \& Practice 5:7-74.

Boocock SS. 1966. An experimental study of the learning effects of two games with simulated 600 environments. American Behavioral Scientist 10:8-17.

601

602

603

604 605 606 607 608 609 610

611

612

613

614
Boyle EA, Duffy T, Dunleavy K. 2003. Learning styles and academic outcome: the validity and utility of Vermunt's Inventory of Learning Styles in a British higher education setting. Br J Educ Psychol 73:267-290.

Brewer C. 2003. Computers in the Classroom: How Information Technology Can Improve Conservation Education. Conservation Biology 17:657-660.

Bromley G. 2000. Environmental games to teach concepts and issues. School Science Review 82:39-46.

Busato VV, Prins FJ, Elshout JJ, Hamaker C. 1998a. Learning styles: a cross-sectional and longitudinal study in higher education. British Journal of Educational Psychology 68:427-441.

Busato VV, Prins FJ, Elshout JJ, Hamaker C. 1998b. The relation between learning styles, the Big Five personality traits and achievement motivation in higher education. Personality and Individual Differences 26:129-140. 
615 Cassidy S. 2004. Learning Styles: An overview of theories, models, and measures. Educational

$616 \quad$ Psychology 24:419-444.

617 Chamorro-Premuzic T, Furnham A, Christopher AN, Garwood J, Neil Martin G. 2008. Birds of a 618 feather: Students' preferences for lecturers' personalities as predicted by their own 619 personality and learning approaches. Personality and Individual Differences 44:965-976.

620 Chamorro-Premuzic T, Furnham A, Lewis M. 2007. Personality and approaches to learning 621 predict preference for different teaching methods. Learning and Individual Differences

622 17:241-250.

623 Coffield F, Moseley D, Hall E, Ecclestone K. 2004. Learning styles and pedagogy in post-16 624 learning: A systematic and critical review. Learning and Skills Research Centre London. 625 Costa PT, McCrae RR. 1992. Four ways five factors are basic. Personality and Individual 626 Differences 13:653-665.

627 De Bello TC. 1990. Comparison of eleven major learning styles models: variables, appropriate 628 populations, validity of instrumentation, and the research behind them. Journal of 629 Reading, Writing, and Learning Disabilities International 6:203-222.

630 Deci EL, Cascio WF, Krusell J. 1975. Cognitive evaluation theory and some comments on the 631 Calder and Staw critique. Journal of Personality and Social Psychology 31:81-86.

632 Deci EL, Koestner R, Ryan RM. 2001. Extrinsic rewards and intrinsic motivation in education: 633 Reconsidered once again. Review of educational research 71:1-27.

634 Dirks C, Wenderoth MP, Withers M 2014. Assessment in the College Science Classroom 635 (Scientific Teaching). $1^{\text {st }}$ ed. United States of America: W.H. Freeman.

636 Diseth $\AA$, Martinsen $\varnothing .2003$. Approaches to learning, cognitive style, and motives as predictors 637 of academic achievement. Educational Psychology 23:195-207. 
638 Dong T, Dontcheva M, Joseph D, Karahalios K, Newman MW, Ackerman MS. 2012.

639 Discovery-based games for learning software. Pages 2083-2086. Proceedings of the 2012

640 ACM annual conference on Human Factors in Computing Systems. ACM, Austin, Texas, 641 USA.

642 Electronic Art 2009. The Sims 3.

643 Ellison MC. 2017. Repeated measures design with Generalized Linear Mixed Models for 644 randomized controlled trials. Journal of Biopharmaceutical Statistics:1-2.

645 Elshout JJ, Akkerman AE 1975. Vijf persoonlijkheidsfaktoren test 5PFT: Handleiding [The Five 646 Personality Factor Test (5PFT): Manual]. Berkhout B.V., Nijmegen, the Netherlands.

647 Entwistle N, Tait H. 1990. Approaches to learning, evaluations of teaching, and preferences for 648 contrasting academic environments. Higher Education 19:169-194.

649 Entwistle NJ, McCune V, Hounsell D 2002. Occassional report 1: Approaches to studying and 650 perceptions of university teaching-learning environments: concepts, measures and preliminary findings. ETL Project, Universities of Edinburgh, Coventry and Durham.

652 Flatla DR, Gutwin C, Nacke LE, Bateman S, Mandryk RL. 2011. Calibration games: making 653 calibration tasks enjoyable by adding motivating game elements. Pages 403-412. Proceedings of the 24th annual ACM symposium on user interface software and technology. ACM, Santa Barbara, CA, USA.

Fransson A. 1977. On qualitative differences in learning: iv-effects of intrinsic motivation and extrinsic test anxiety on process and outcome. British Journal of Educational Psychology 47:244-257.

659 Fritschner LM. 2000. Inside the undergraduate college classroom. The Journal of Higher $660 \quad$ Education 73: 342-362. 
661 Garris R, Ahlers R, Driskell JE. 2002. Games, motivation, and learning: a research and practice 662 model. Simulation \& Gaming 33:441-467.

663 Gilhead E, Milburn R 2016. Conservation Crisis. Tunza Games Ltd, England.

664 Halan S, Rossen B, Cendan J, B. L. 2010. High Score!-Motivation Strategies for User

665 Participation in Virtual Human Development. Pages 482-488. Proceedings of the

666 international conference on Intelligent Virtual Agents. Springer-Verlag, Springer

667 Berlin/Heidelberg.

668 Hanus MD, Fox J. 2015. Assessing the effects of gamification in the classroom: A longitudinal 669 study on intrinsic motivation, social comparison, satisfaction, effort, and academic $670 \quad$ performance. Computers \& Education 80:152-161.

671 Hewitt P. 1997. Games in instruction leading to environmentally responsible behavior. The 672 Journal of Environmental Education 28:35-37.

673 Hill J, Ray CK, Blair JR, Carver Jr CA. 2003. Puzzles and games: addressing different learning styles in teaching operating systems concepts. Pages 182-186. ACM SIGCSE Bulletin. ACM.

Hungerford HR, Volk TL. 1990. Changing Learner Behavior Through Environmental Education. The Journal of Environmental Education 21:8-21.

678 Jacobson SK, McDuff M, Monroe M 2015. Conservation education and outreach techniques. $679 \quad$ Oxford University Press.

680 Jonsson A, Svingby G. 2007. The use of scoring rubrics: Reliability, validity and educational 681 consequences. Educational Research Review 2: 130-144.

682 Kiili K. 2005. Digital game-based learning: Towards an experiential gaming model. The Internet 683 and Higher Education 8:13-24. 
684 Kimatian S, Lloyd S, Berger J, Steiner L, McKay R, Schwengal D. 2017. Undirected learning 685 styles and academic risk: Analysis of the impact of stress, strain and coping. J Educ $686 \quad$ Perioper Med 19:E603.

687 Kinzie MB, Joseph DRD. 2008. Gender differences in game activity preferences of middle 688 school children: implications for educational game design. Educational Technology 689 Research and Development 56:643-663.

690 Kirriemuir J, McFarlane A. 2004. Literature review in games and learning. Available from 691 https://www.nfer.ac.uk/publications/FUTL27/FUTL27literaturereview.pdf (accessed 12 692 Dec 2017).

693 Klein JD, Freitag E. 1991. Effects of Using an Instructional Game on Motivation and 694 Performance. The Journal of Educational Research 84:303-308.

695 Kolb D. 1984. Experiential Learning: Experience as the Source of Learning and Development 696 Englewood Cliffs. NJ:. Prentice Hall

697 Kramer A, Bhave DP, Johnson TD. 2014. Personality and group performance: The importance of 698 personality composition and work tasks. Personality and Individual Differences 58:132$699 \quad 137$.

700 Krathwohl DR. 2002. A revision of Bloom's Taxonomy: an overview. Theory Into Practice 41: 701 212-218.

702 Lara MA. 2013. Personality traits and performance in online game-based learning: collaborative 703 versus individual settings. Department of Instructional Systems Technology of the School of Education Thesis. Indiana University, Indiana. 
705 Lawal B. 2014. Repeated Measures Design. Pages 697-718 in Lawal B, ed. Applied Statistical

706 Methods in Agriculture, Health and Life Sciences. Springer International Publishing,

707 Cham.

708 Mahar MT, Murphy SK, Rowe DA, Golden J, Shields AT, Raedeke TD. 2006. Effects of a

709 classroom-based program on physical activity and on-task behavior. Medicine 7 Science

$710 \quad$ in Sports \& Exercise 38:2086 -2094.

711 McAuley E, Duncan T, Tammen VV. 1989. Psychometric properties of the Intrinsic Motivation

712 Inventory in a competitive sport setting: A confirmatory factor analysis. Research

713 quarterly for exercise and sport 60:48-58.

714 McCoy BR. 2016. Digital distractions in the classroom phase II: student classroom use of digital

715 devices for non-class related purposes. Journal of Media Education 7: 5 - 32 .

716 Mount MK, Barrick MR, Strauss JP. 1994. Validity of observer ratings of the big five

717 personality factors. Journal of Applied Psychology 79:272.

718 Mustapha SM, Rahman NSNA, Yunus MM. 2010. Perceptions towards classroom participation:

719 A case study of Malaysian undergraduate students. Procedia - Social and Behavioural

$720 \quad$ Sciences. 7: 113-121.

721 Oxford University. 2017. Research ethics (including CUREC), Available from

722 https://researchsupport.admin.ox.ac.uk/governance/ethics (accessed 12 Dec 2017).

723 Özyurt Ö, Özyurt H. 2015 Learning style based individualized adaptive e-learning environments:

724 Content analysis of the articles published from 2005 to 2014. Computer in Human

$725 \quad$ Behaviour 52:349-358.

726 Pashler H, McDaniel M, Rohrer D, Bjork R. 2009. Learning styles: concepts and evidence.

727 Psychological Science in the Public Interest 9: 105-119. 
728 Project WILD K-12 Curriculum and Activity Guide. 2000. Council for Environmental

729 Education, Houston, TX.

730 Quinn MM, Smith T, Kalmar EL, Burgoon JM. What type of learner are your students?

731 Preferred learning styles of undergraduate gross anatomy students according to the index 732 of learning styles questionnaire. Anatomical Sciences Education:n/a-n/a.

733 Rapeepisarn K, Wong KW, Fung CC, Khine MS. 2008. The Relationship between Game Genres, 734 Learning Techniques and Learning Styles in Educational Computer Games. Pages 497508 in Pan Z, Zhang X, El Rhalibi A, Woo W, and Li Y, editors. Technologies for ELearning and Digital Entertainment: Third International Conference, Edutainment 2008 Nanjing, China, June 25-27, 2008 Proceedings. Springer Berlin Heidelberg, Berlin, Heidelberg.

Redpath SM, Young J, Evely A, Adams WM, Sutherland WJ, Whitehouse A, Amar A, Lambert RA, Linnell JDC, Watt A, Gutiérrez RJ. 2013. Understanding and managing conservation conflicts. Trends in Ecology and Evolution 28:100-109.

Richardson M, Abraham C, Bond R. 2012. Psychological correlates of university students' academic performance: a systematic review and meta-analysis. Psychological Bulletin 138:353-387.

Ryan RM, Koestner R, Deci EL. 1991. Ego-involved persistence: When free-choice behavior is not intrinsically motivated. Motivation and Emotion 15:185-205.

747 School RoHC 2013. Freahwater Board Game. Department of Conservation, New Zealand.

Shuttleworth M. 2009a. Counterbalanced measures design. Retrieved from Experiment 
750 Shuttleworth M. 2009b. Counterbalanced Measures Design., Available from

751 https://explorable.com/counterbalanced-measures-design (accessed Dec 09 2017).

752 Smith A-L, Baker L. 2011. Getting a clue: creating student detectives and dragon slayers in your 753 library. Reference Services Review 39:628-642.

754 Swallow E. 2012. Creating Innovators: Why America's Education System Is Obsolete Available 755 from http://www.forbes.com/sites/ericaswallow/2012/04/25/creating-innovators/ (accessed 12 Dec 2017).

Tait H, Entwistle N. 1996. Identifying students at risk through ineffective study strategies. Higher Education 31:97-116.

Tango T 2017. Repeated Measures Design with Generalized Linear Mixed Models for Randomized Controlled Trials. London: Chapman and Hall/CRC Press.

Tilbury D. 1995. Environmental education for sustainability: Defining the new focus of

Tsigilis N, Theodosiou A. 2003. Temporal stability of the intrinsic motivation inventory. Perceptual and Motor Skills 97:271-280.

Tsingos C, Bosnic-Anticevich S, Smith L. 2015. Learning styles and approaches: Can reflective strategies encourage deep learning? Currents in Pharmacy Teaching and Learning 7: 492504

768

Vansteenkiste M, Lens W, Deci EL. 2006. Intrinsic versus extrinsic goal contents in selfdetermination theory: another look at the quality of academic motivation. Educational Psychologist 41:19-31.

771 Vermunt JD. 1998. The regulation of constructive learning processes. British Journal of

$772 \quad$ Educational Psychology 68:149-171. 
773 Vermunt JDHM. 1994. Inventory of learning styles in higher education; scoring key for the 774 inventory of learning styles in higher education.

775 von Ende CN. 2001. Repeated-measures analysis. Design and analysis of ecological

776 experiments. Oxford University Press, Oxford:134-157.

777 Wagner T, Compton RA 2015. Creating innovators: The making of young people who will $778 \quad$ change the world. Simon and Schuster.

779 Wang LC, Chen MP. 2010. The effects of game strategy and preference-matching on flow 780 experience and programming performance in game-based learning. Innovations in $781 \quad$ Education and Teaching International 47:39-52. 
Figure 1 (on next page)

Experimental design

(A) Repeated measures design. Each student experienced two lesson types (DI, EG, SG) in either the order Al or the order All. Where possible, we alternated the order (Al versus All) of the lesson type for different topics and for different groups of students (please see Table 2 for details). (B) Counterbalanced measures design. Students were divided into two groups and one group is treated with lesson type $A$, followed by lesson type $B$, and the other is tested with lesson type B followed by lesson type A. 
A

Order AI

Session 1

Session 2

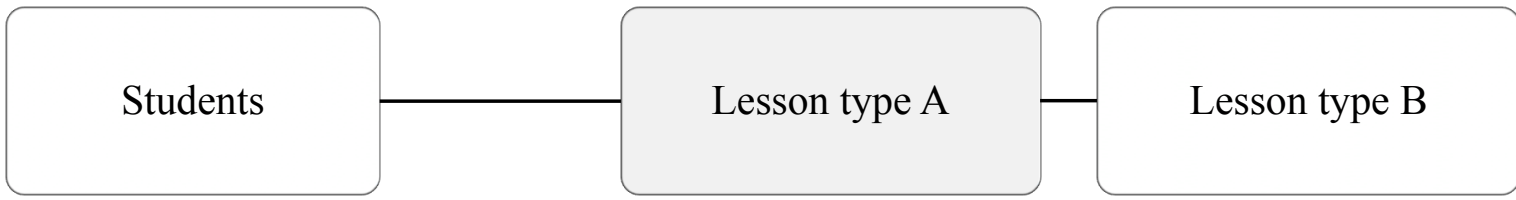

Order AII

Session 1

Session 2

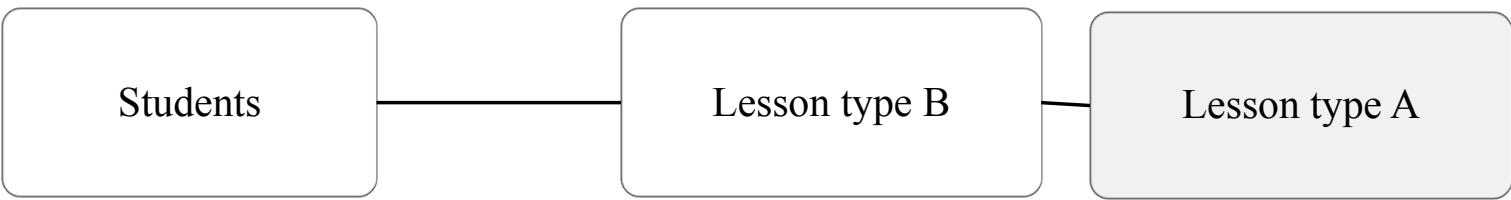

B

Session 1

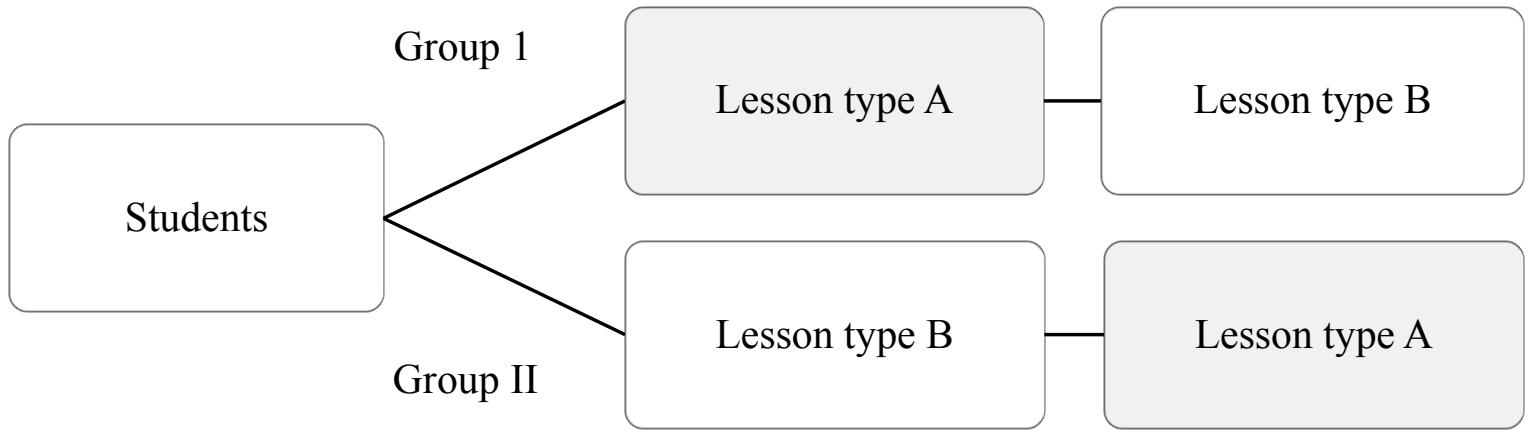




\section{Figure 2 (on next page)}

\section{Perception}

Students' perception of the different lesson types as analysed with ordinal logistic models. Students rated their bondedness with their team peers before and after lessons and the $y$ axis shows the after-lesson relationship rating minus that of before-lesson. For each lesson type, the mean perception scores of students are shown. Error bars denote standard errors of sample size (i.e. number of student). Sample sizes are indicated in brackets on the x-axis, sample sizes vary because a few of the questions in the questionnaire were altered between years. Different letters above bars denote significant differences, details of results are shown in Tables S1 and S2. (A) Knowledge acquisition parameters; (B) Development parameters; (C) Class dynamics parameters; (D) Intrinsic motivation parameters, 'interest or enjoyment' is considered the self-report measure of intrinsic motivation, 'perceived competence', 'perceived choice' are positive predictors of intrinsic motivation while 'pressure or tension' is a negative predictor of intrinsic motivation. (E) Bondedness rating, considered a positive predictor of the intrinsic motivation. 
A

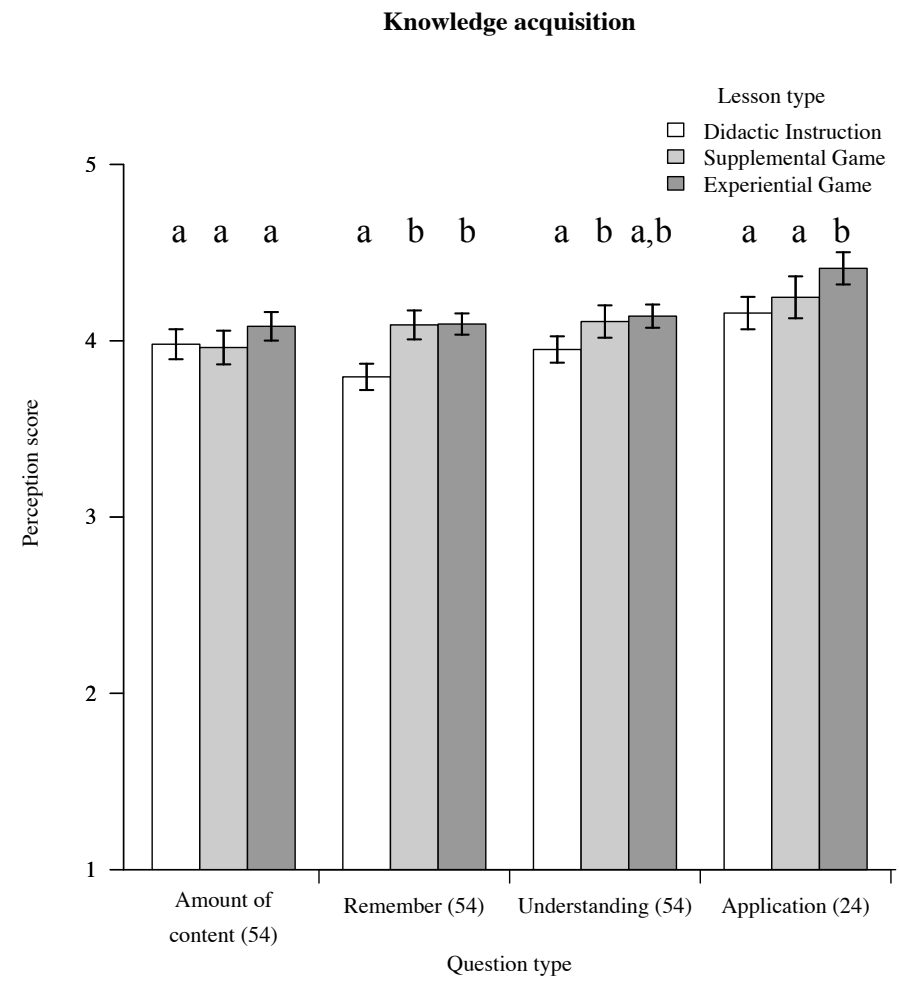

B

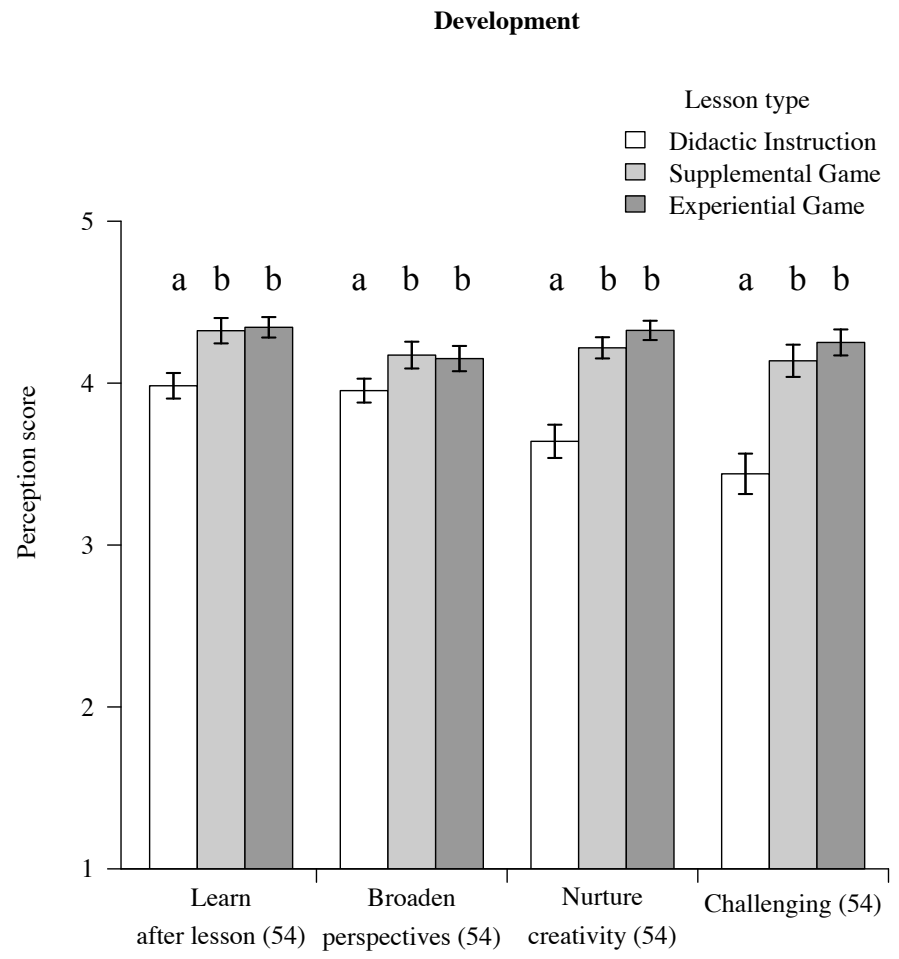

Question type 
$\mathrm{C}$

Class dynamics

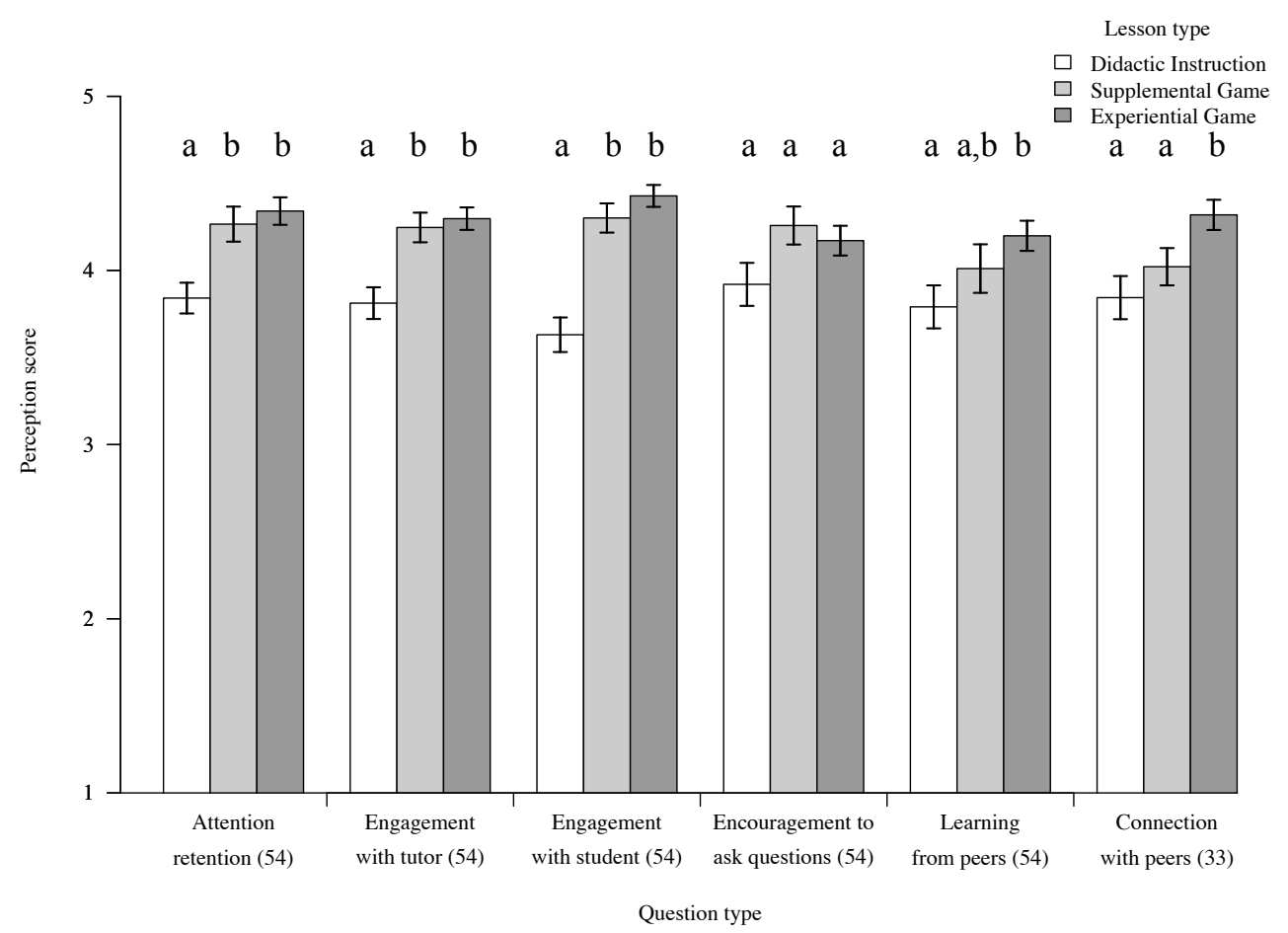

$\mathrm{D}$

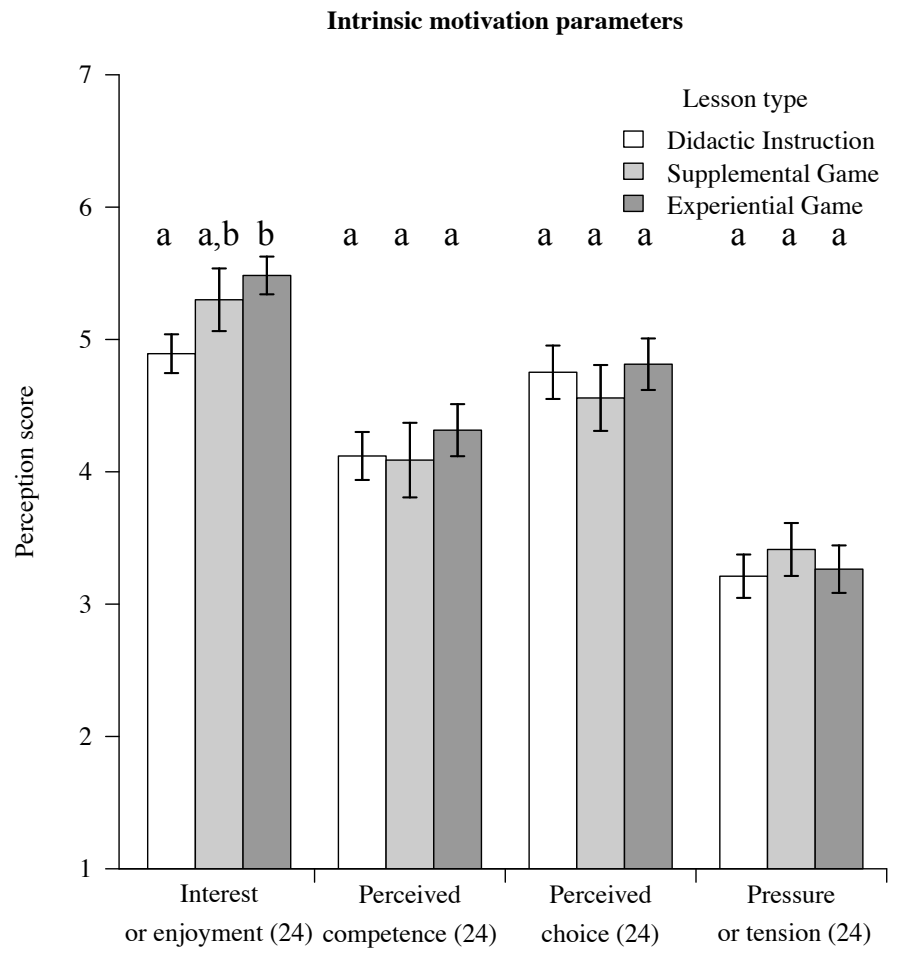

Question type 


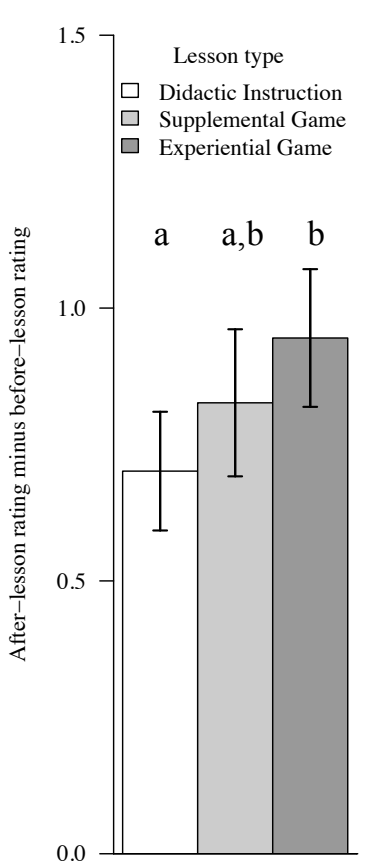


Figure 3 (on next page)

Behaviour

Students' behavioural responses to the different lesson types. The probability of behaviour was analysed with a Generalised linear mixed model with Binomial error distribution and frequency of occurrence was analysed with a Generalised linear mixed model with Poisson error distribution. Error bars denote standard errors of sample size $(n=54)$. Different letters above bars denote significant differences, details of results are shown in Tables S3 and S4.
(A) Probability of behaviour occurrence; (B) Frequency of occurrence. 
A

Probability of occurrence

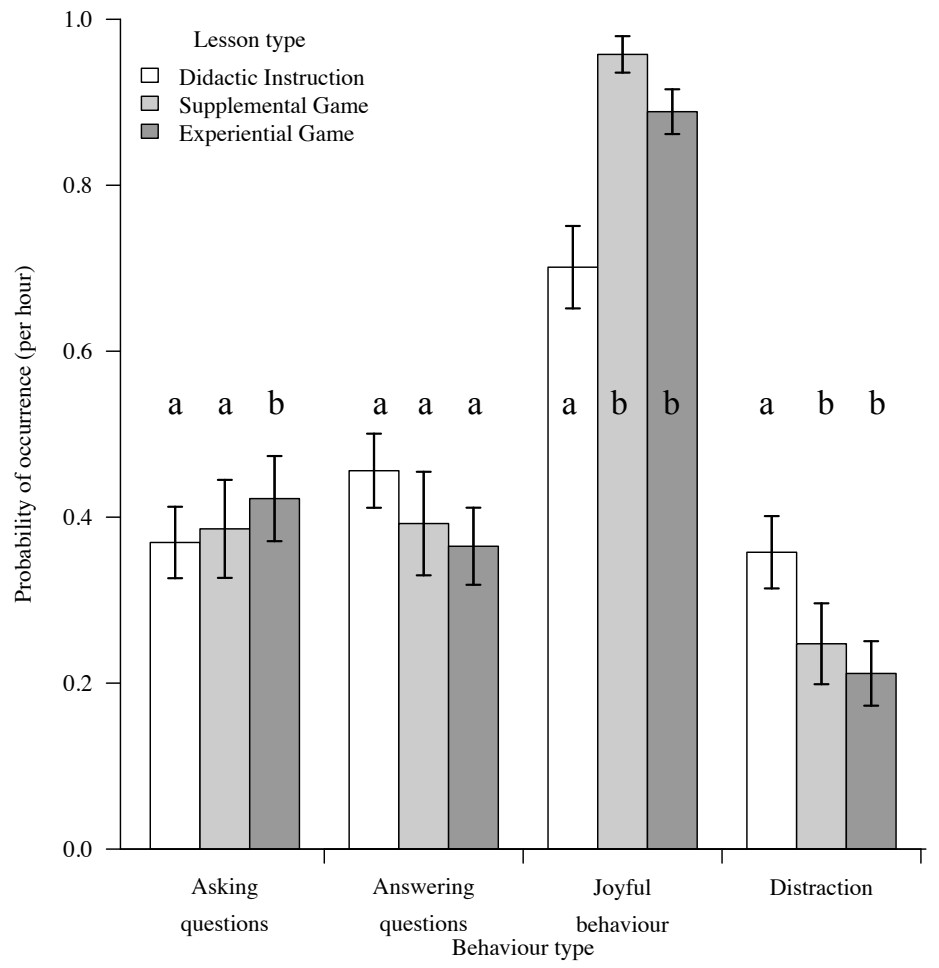

Rate of occurrence

B

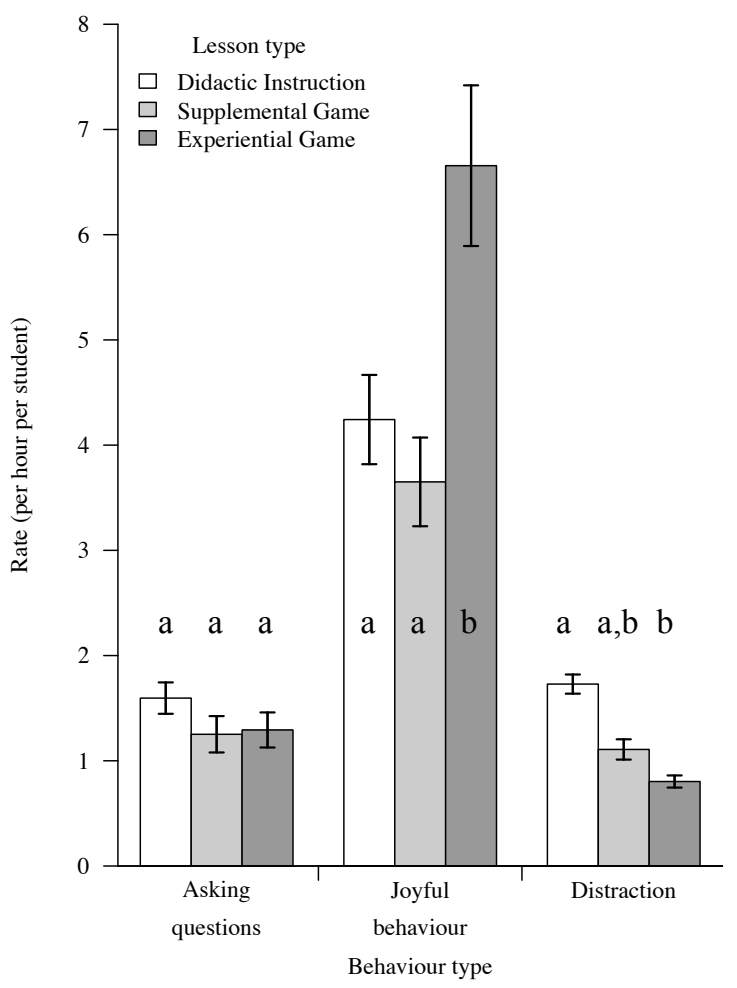


Figure 4 (on next page)

Learning

Learning as measured by proportion of quiz questions correct before, after or one-week post lesson. Questions were the same before, after or one-week post lesson and varied in their difficulty and discrimination levels (Table S5). The y-axis shows the proportion of questions correct and this was analysed with Generalised Linear Mixed Models with Binomial error distribution. Error bars denote standard errors of sample size $\left(n_{\text {both years }}=55 ; n_{\text {year } 2015}=30\right.$; year $2016=25$ ). Details of results are shown in Table S5. DI - Didactic Instruction; SG Supplemental Game; EG - Experiential Game. Different lines denote different lesson types. (A) Both years; (B) Year 2015; (C) Year 2016. 
A Both years

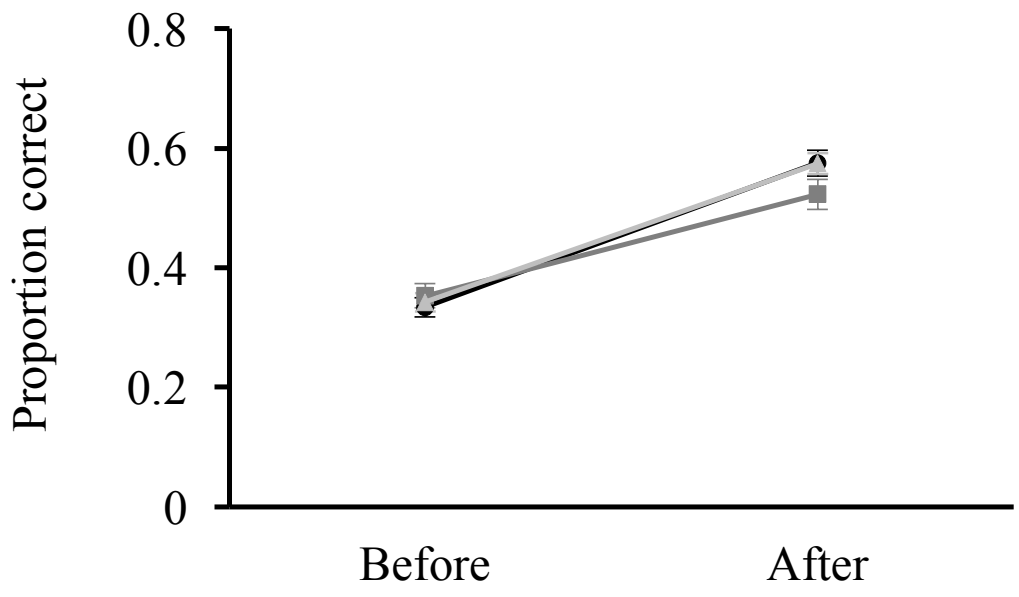

B $\quad$ Year 2015

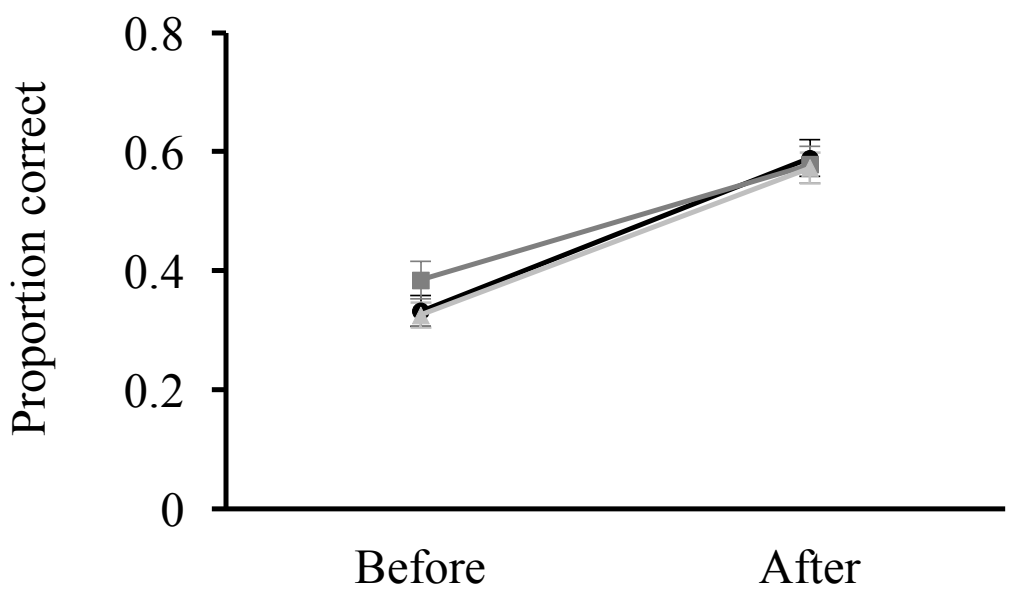

C $\quad$ Year 2016

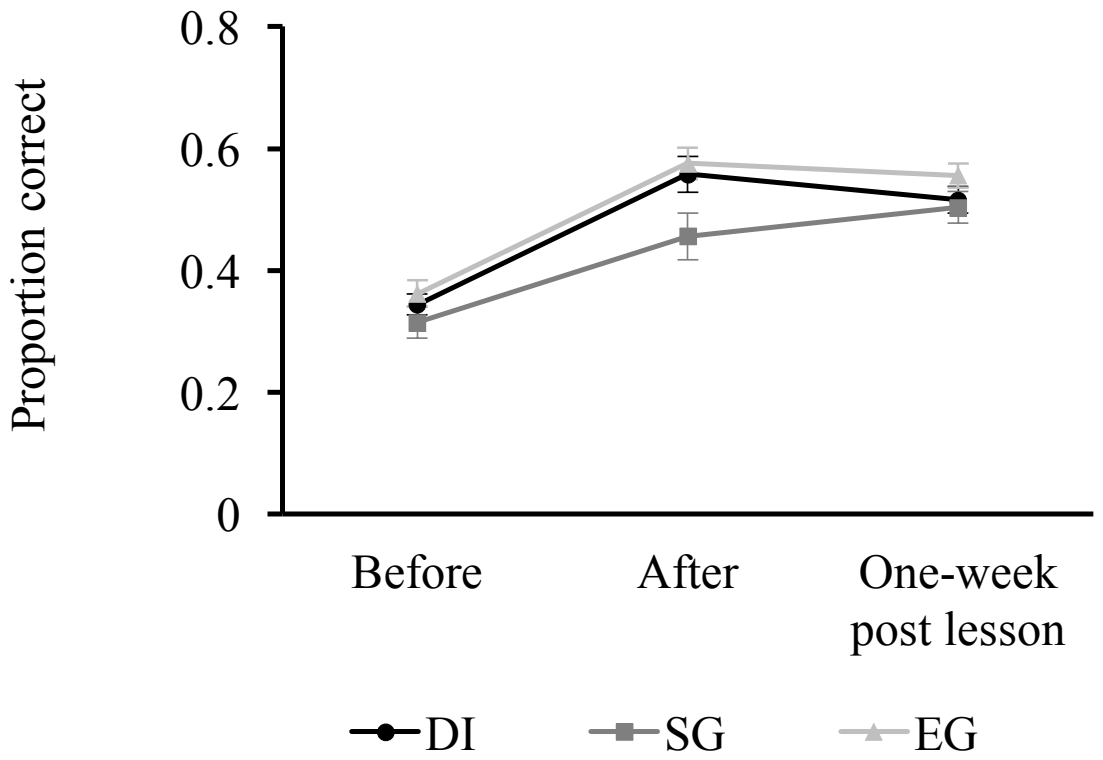




\section{Table $\mathbf{1}$ (on next page)}

\section{Cohort demographics table}

Repeated-measures design: a single group of students were taught the first session with one lesson type and then the second session with another lesson type. Counterbalanced design: class was divided into two groups and both were subjected to a two-session lesson. During the first session, one group underwent one lesson type and the other underwent the other lesson type. In the second session, the treatments were swapped and thus each group experienced both types of lesson in a balanced ordered manner. Details on the experimental design used and content taught for each topic and session are provide in Table 2. 
1 Table 1. Cohort demographics table. Repeated-measures design: a single group of students were taught the first session with one

2 lesson type and then the second session with another lesson type. Counterbalanced design: class was divided into two groups and both

3 were subjected to a two-session lesson. During the first session, one group underwent one lesson type and the other underwent the

4 other lesson type. In the second session, the treatments were swapped and thus each group experienced both types of lesson in a

5 balanced ordered manner. Details on the experimental design used and content taught for each topic and session are provide in Table

62.

7

8

\begin{tabular}{|c|c|c|c|c|c|c|c|}
\hline Course & Year & Location & $\begin{array}{l}\text { Number } \\
\text { of } \\
\text { students }\end{array}$ & $\begin{array}{l}\text { Gender } \\
\text { distribution }\end{array}$ & $\begin{array}{l}\text { Age } \\
\text { distribution } \\
\text { (years) }\end{array}$ & Notes on questionnaire on perception & $\begin{array}{l}\text { Experimental } \\
\text { design (Number of } \\
\text { topics) }\end{array}$ \\
\hline $\begin{array}{l}\text { Wildlife } \\
\text { Conservation } \\
\text { Course }\end{array}$ & 2015 & $\begin{array}{l}\text { University of } \\
\text { Nottingham } \\
\text { Malaysia Campus }\end{array}$ & 21 & $\begin{array}{l}10 \text { males; } \\
11 \text { females }\end{array}$ & $\begin{array}{l}1(<20) \\
8(21-25) \\
8(26-30) \\
2(31-35) \\
2(>35)\end{array}$ & $\begin{array}{l}\text { In section 1, the statements 'Appreciation of } \\
\text { application' and 'Degree of connection with } \\
\text { peers' were not in the questionnaire. Section } \\
2 \text { on intrinsic motivation and section } 3 \text { on } \\
\text { bondedness were not in the questionnaire. }\end{array}$ & $\begin{array}{l}\text { Counterbalanced } \\
\text { measures design ( } 3 \text { ); } \\
\text { Repeated measures } \\
\text { design (1) }\end{array}$ \\
\hline $\begin{array}{l}\text { Wildlife } \\
\text { Conservation } \\
\text { Course }\end{array}$ & 2016 & $\begin{array}{l}\text { University of } \\
\text { Nottingham } \\
\text { Malaysia Campus }\end{array}$ & 16 & $\begin{array}{l}4 \text { males; } \\
12 \text { females }\end{array}$ & $\begin{array}{l}8(21-25) \\
4(26-30) \\
2(31-35) \\
2(>35)\end{array}$ & $\begin{array}{l}\text { All sections and questions were in the } \\
\text { questionnaire }\end{array}$ & $\begin{array}{l}\text { Counterbalanced } \\
\text { measures design (3); } \\
\text { Repeated measures } \\
\text { design (2) }\end{array}$ \\
\hline
\end{tabular}


Diploma in

International

Wildlife

Conservation

Practice

Diploma in

International

Wildlife

Conservation

Practice

\section{University of Oxford Wildlife \\ Conservation \\ Research Unit}
2016 University of Oxford Wildlife
Conservation
Research Unit

Total
8

4 males;

4 females

2 (21-25);

5 (26-30);

$1(>35)$
$8+2 \quad 5$ males; $\quad 2(21-25)$
5 females $\quad 7(26-30)$;
$1(31-35)$

55

$\begin{array}{ll}23 \text { males; } & 1(<20) ; \\ 32 \text { females } & 20(21-25) ; \\ & 24(26-30) ; \\ & 5(31-35) ; \\ & 5(>35)\end{array}$

In section 1, the statement 'Appreciation of application' with peers' was not in the questionnaire. Section 2 on intrinsic motivation and section 3 on bondedness were not in the questionnaire

All sections and questions were in the questionnaire
Repeated measures

design (3)

Repeated measures design (5)

\section{9}




\section{Table 2 (on next page)}

Topics taught during the Wildlife Conservation Course (WCC) and Diploma in International Wildlife Conservation Practice and the experimental design used.

Details on the experiential gaming (EG) task or supplemental game (SG) task assigned to the teams are provided. Repeated-measures design: a single group of students were taught the first session with one lesson type and then the second session with another lesson type. Counterbalanced design: class was divided into two groups and both were subjected to a two-session lesson. During the first session, one group underwent one lesson type and the other underwent the other lesson type. In the second session, the treatments were swapped and thus each group experienced both types of lesson in a balanced ordered manner. 
1 Table 2. Topics taught during the Wildlife Conservation Course (WCC) and Diploma in International Wildlife Conservation Practice

2 and the experimental design used. Details on the experiential gaming (EG) task or supplemental game (SG) task assigned to the teams

3 are provided. Repeated-measures design: a single group of students were taught the first session with one lesson type and then the

4 second session with another lesson type. Counterbalanced design: class was divided into two groups and both were subjected to a two-

5 session lesson. During the first session, one group underwent one lesson type and the other underwent the other lesson type. In the

6 second session, the treatments were swapped and thus each group experienced both types of lesson in a balanced ordered manner.

7

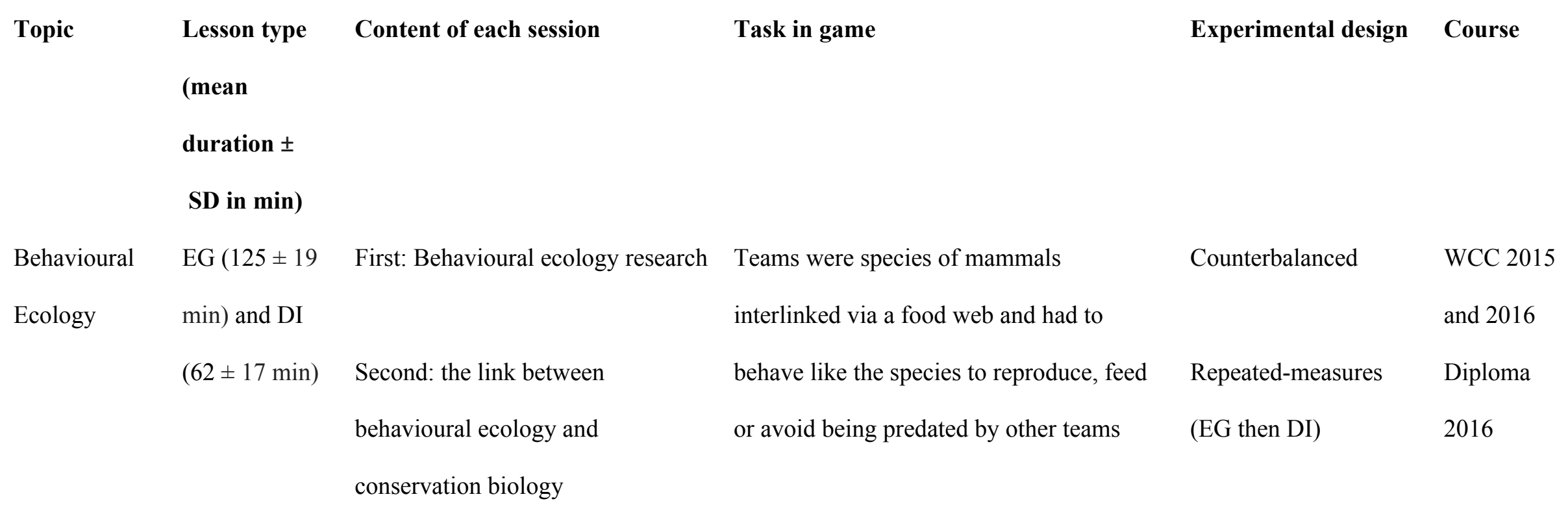




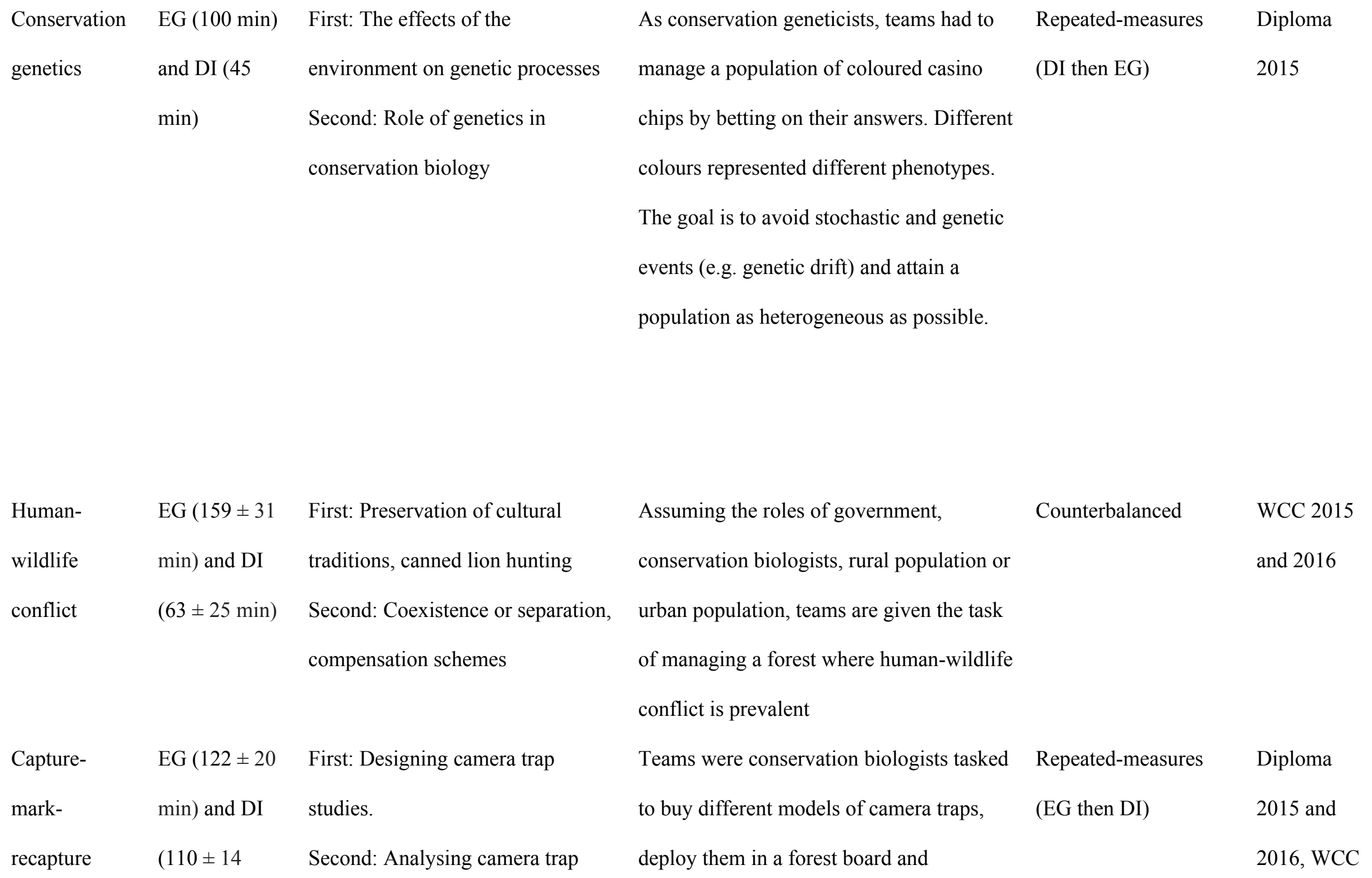


reveal the density of clouded leopards

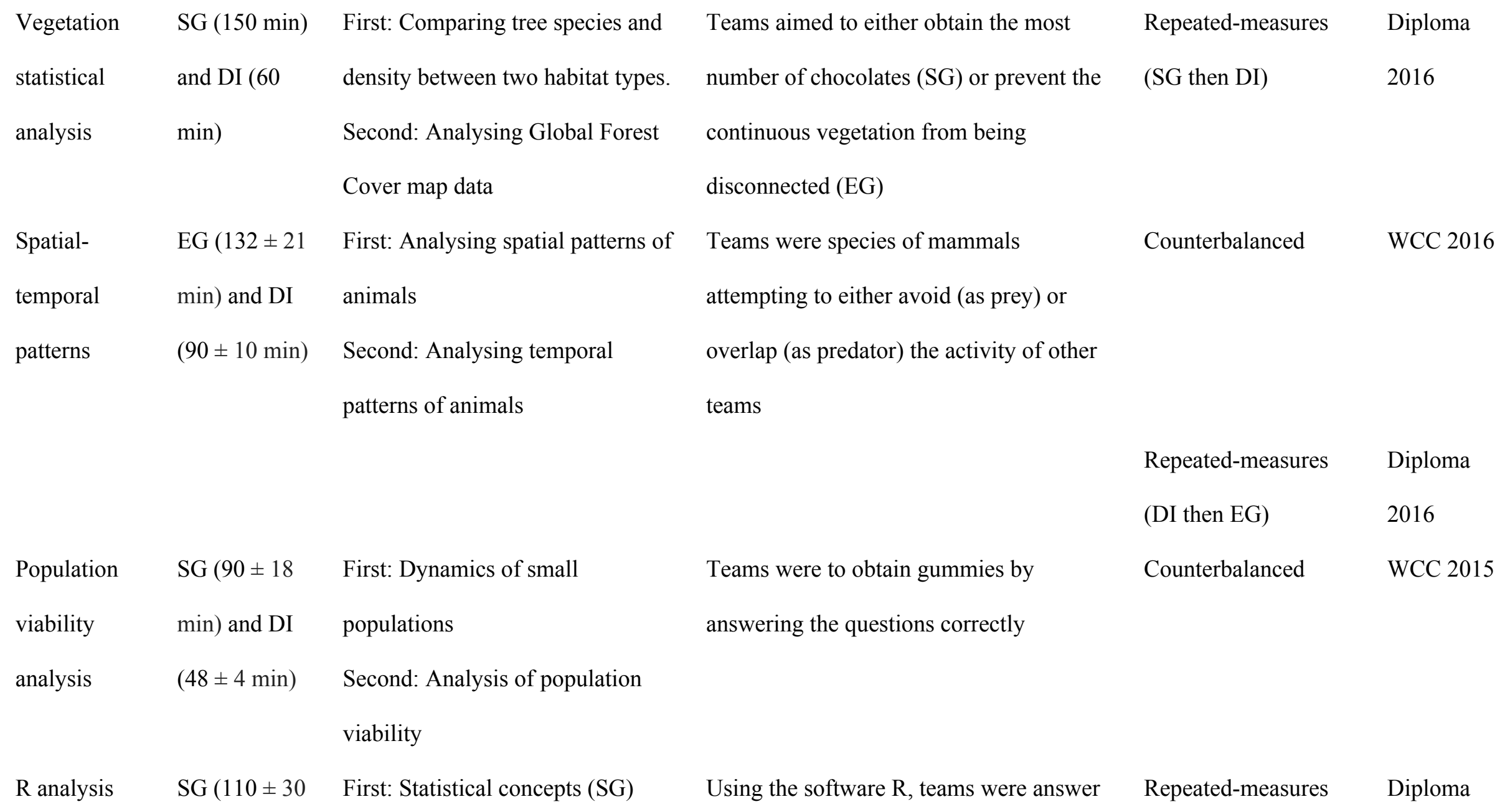




$\begin{array}{lllll}\min ), \mathrm{DI}(80 & \text { Second: Hypothesis testing (DI) } & \text { questions in order to advance forward on a } & \text { (SG then EG) } & 2015, \text { WCC } \\ \text { min) and EG } & \text { Third: Experimental design (EG) } & \text { game board (SG) or to obtain tokens for } & & 2015,2016 \\ (120 \pm 16 & & \text { designing an experiment (EG) } & \text { Repeated-measures } & \text { Diploma } \\ \min ) & & \text { (SG then DI then EG) 2016 }\end{array}$

